\title{
TOWARD A COLLECTIVE INTELLIGENCE RECOMMENDER SYSTEM FOR EDUCATION
}

\author{
Jaime Meza' ${ }^{1}$, L. Vaca ${ }^{2}$, Ester Simó ${ }^{1}$, Joseph Monguet ${ }^{1}$ \\ ${ }^{1}$ Universitat Politécnica de Catalunya (SPAIN) \\ ${ }^{2}$ Escuela Superior Politécnica de Chimborazo (ECUADOR)
}

\begin{abstract}
.
The development of Information and Communication Technology (ICT), have revolutionized the world and have moved us into the information age, however the access and handling of this large amount of information is causing valuable time losses. Teachers in Higher Education especially use the Internet as a tool to consult materials and content for the development of the subjects. The internet has very broad services, and sometimes it is difficult for users to find the contents in an easy and fast way. This problem is increasing at the time, causing that students spend a lot of time in search information rather than in synthesis, analysis and construction of new knowledge. In this context, several questions have emerged: Is it possible to design learning activities that allow us to value the information search and to encourage collective participation?. What are the conditions that an ICT tool that supports a process of information search has to have to optimize the student's time and learning?.
\end{abstract}

This article presents the use and application of a Recommender System (RS) designed on paradigms of Collective Intelligence $(\mathrm{Cl})$. The RS designed encourages the collective learning and the authentic participation of the students.

The research combines the literature study with the analysis of the ICT tools that have emerged in the field of the $\mathrm{Cl}$ and RS. Also, Design-Based Research (DBR) was used to compile and summarize collective intelligence approaches and filtering techniques reported in the literature in Higher Education as well as to incrementally improving the tool.

Several are the benefits that have been evidenced as a result of the exploratory study carried out. Among them the following stand out:

- It improves student motivation, as it helps you discover new content of interest in an easy way.

- It saves time in the search and classification of teaching material of interest.

- It fosters specialized reading, inspires competence as a means of learning.

- It gives the teacher the ability to generate reports of trends and behaviors of their students, real-time assessment of the quality of learning material.

The authors consider that the use of ICT tools that combine the paradigms of the $\mathrm{Cl}$ and RS presented in this work, are a tool that improves the construction of student knowledge and motivates their collective development in cyberspace, in addition, the model of Filtering Contents used supports the design of models and strategies of collective intelligence in Higher Education.

Keywords: Collective intelligence, Higher education, Recommender System, ICT tools.

\section{INTRODUCTION}

We live in the information age, however, are we actually using the information in productive tasks? or, its access and management it's causing valuable losses of times in the information sea?. We try to response these questions in the next paragraphs.

The collaboration among colleagues has been always important through the time. Thanks to the fast evolution of Information Technology and Computer Science, we have seen many collaboration based applications. They are usually called Collective Intelligence $(\mathrm{Cl})$. In order to solve a lot of problems, people can share their experiences and knowledge with other people through different online ICT tools [1].

The main idea is to bring together researchers and engineers in areas of computational collective intelligence to share their visions, research results, and experiences, this analysis will give an opportunity to step further the discussion on the potential of collective intelligence across many different communities and areas [1]. As [2] report a psychometric methodology for quantifying a factor 
termed "collective intelligence", which reflects how well groups perform on a similarly diverse set of group problem-solving tasks.

Now we are in Big Data Age. This is of course a scientific revolution on computer-supported collaborative works. Transforming Big Data into Big Knowledge and developing a Knowledge-Based System require new visions and approaches in order to provide people with better collaborations using ICTs. [1]. Collective intelligence by social network analytics [3] reports an interesting framework on temporal fuzzy concept analysis for studying social content evolution along time and semantic dimensions. This work extends the goals of the topic detection and tracking (TDT). The paper, "associative engines based approach supporting collaborative analytics in the Internet of cultural things", presents an Internet of Things-based application by using collective intelligence technologies. They analyzed museum visitors' behavior [4]. The paper published by [5], reports the concept of representing the experiences from users. Particularly, they show an application on manufacturing domain. The main contribution of this paper proposes an experience-based collective intelligence model. Additionally [6], present an interesting approach on context representation for Complex Event Processing (CEP). This study was focusing on temporal probabilistic model for handling dynamic rules on collective intelligence; finally [7] show a novel platform for acquiring and processing the contextual big data from mobile devices. This mobile context management system is based on rule-based user profiling for reasoning with ambiguous and uncertain data.

As we can see there are several efforts in the field of collective intelligence \& recommender systems, therefore we focus on combine both for exploring the affectivity of a new approach for increasing the students learning, and make decision in real time for teachers.

\section{STATE OF ART \& RELATED WORKS}

Currently, higher education institutions have been forced to change from their traditional tasks of teaching and research towards an economic and cultural development knew as the third mission. This third mission includes an external relationship to get technology transfer and innovation; continuing education; and social engagement as mentioned (Veltri et al., 2014; Leitner and Warden, 2004; Sánchez et al., 2009) cited by [19].

In this view Collective Intelligence $(\mathrm{Cl})$ plays an important role, this not new term as was said by (Lévy, 1994; Pór, 1995; Malone et al., 2008) cited by [19] appeared at the end of 1970 and has exploited in the last ten years where local and distributed assets and expertise are coordinated to achieve a collective aim [19]. $\mathrm{Cl}$ is defined as the combination of behavior choices or ideas from a group of people in order to create new ideas. Usually the survey is the basic form of $\mathrm{Cl}$ [21].

Nowadays, a new kind of Collective Intelligence has been enabled by the Internet and for the enormous quantity of information generated every single second (Malone T, 2017 https://www.edge.org/conversation/thomas_w_malone-collective-intelligence). For instance, the famous online encyclopedia Wikipedia is the result of users' additions (http://www.wikipedia.org/).

Recommender systems (RS) are useful to recommend items found on users previous choices [8]. In the field of RS there are some efforts to offer new and better recommendations for increasing performance. RSs are software tools and techniques that provide suggestions for articles to be useful to a user. The suggestions provided are intended to support your users in various decision-making processes, such as what items to buy, what music to listen to, or what news to read. Recommendation systems have proven to be a valuable means for online users to cope with information overload and have become one of the most powerful and popular tools in e-commerce. A number of techniques have been proposed for the generation of recommendations and during the last decade many of them have also been successfully deployed in commercial environments [25]. In addition, [25] point out that RS development is a multidisciplinary effort involving experts from various fields such as Artificial Intelligence, Human Computer Interaction, Information Technology, Data Mining, Statistics, Adaptive User Interfaces, Marketing or Consumer Behavior.

The RS has been applied with commercial focus, however over time this tendency has been changed to new domains such as health, education and government. [11] Presented a framework titled: "Automated collaborative filtering (ACF) systems predict a person's affinity for articles or information by connecting that person's interests with the registered interests of a community of People and sharing skills among like-minded people. 
In education, according to [10], who cites (Chen and Pu 2014; Chen 2011; Ozok, Fan, and Norcio 2010) RS are becoming useful and popular in different areas, in the educational field RS had been reported in several articles regarding to documentation management (Weng and Chang 2008), complementary materials for courses (Bobadilla et al. 2013; Hsu 2008), select e-courses (Hsu 2008; Bodea, Dascalu, and Lipai 2012). All these researchers suggest different ways to match the user's profiles with the data to be recommend, allowing the user to have proper suggestions according with their learning manner [10].

Some researchers have pointed to other approaches to content filtering. For example, Burke (2007) presents six approaches. However, there are traditionally three approaches to content filtering, these are categorized into: Content-Based: Try to recommend a similar article according to the user's preference in the past; Collaborative filtering: Identifies users whose tastes are similar to those of a particular user and recommends to this user content that other users like, and hybrid is a combination of the latter two approach. On the other hand, the Collective Intelligence system and recommendation emerge. For instance: (Oh, Jeong, \& Lee, 2013), (Patel \& Balakrishnan, 2009), (Ryang, Yun, Pyun, Lee, \& Kim) have informed several results on the recommender system and Collective Intelligence.

Also, exist other recommendation systems based on data mining techniques as classification algorithms and association rules [17]. According with [17] usually data mining techniques are used in e-learning environments, because they permit to discover the patterns applied by students in online courses.

It should also be noted that a determining factor in the design of a system of recommendations is the filtering model that is used according to the type of system, then a summary is presented that supports the selection of the RS approach (Table 1).

Table 1. Filtering approach

\begin{tabular}{l|l}
\hline \hline Approach & Description \\
\hline Content-based & $\begin{array}{l}\text { The system learns to recommend items that are similar to the ones that the } \\
\text { user liked in the past. [9] }\end{array}$ \\
\hline Collaborative filtering & $\begin{array}{l}\text { The simplest and original implementation of this approach recommends to } \\
\text { the active user the items that other users with similar tastes liked in the past } \\
\text { [25]. }\end{array}$ \\
\hline Demographic & $\begin{array}{l}\text { This type of system recommends items based on the demographic profile of } \\
\text { the user [13]. }\end{array}$ \\
\hline Knowledge-based & $\begin{array}{l}\text { Knowledge-based systems recommend items based on specific domain } \\
\text { knowledge about how certain item features meet users needs and } \\
\text { preferences and, ultimately, how the item is useful for the user [26, 27] cited } \\
\text { by [25]. }\end{array}$ \\
\hline Community-based. & $\begin{array}{l}\text { This type of system recommends items based on the preferences of the } \\
\text { users friends. This technique follows the epigram "Tell me who your friends } \\
\text { are, and I will tell you who you are". [28, 29] cited by [25]. }\end{array}$ \\
\hline $\begin{array}{l}\text { Hybrid recommender } \\
\text { systems }\end{array}$ & $\begin{array}{l}\text { Hybrid systems exploit characteristics of content-based and collaborative } \\
\text { systems, due to the complementary nature of both, to overcome the } \\
\text { drawbacks of both systems to obtain better recommendations [30]. }\end{array}$ \\
\hline \hline
\end{tabular}

\section{METHOD \& PROPOSAL MODEL}

The research combines the study of the literature with the analysis of the ICT tools that have emerged in the field of the $\mathrm{Cl}$ and RS. Design-Based Research (DBR) was used to compile and summarize collective intelligence approaches and filtering techniques reported in the literature in the field of Higher Education as well as to incrementally adjust the tool. 
The proposal model is splitting in two components: On the one hand the instructional design, and the other the recommender engine.

\subsection{Instructional design}

The instructional design has been designed by two stages and some tasks by stages, as we show to follow.

Planning.- These are activities prior to the use of the activity in the classroom, in which the teacher in the development of his curriculum or syllabus should establish:

1. Contents to be used, this compilation will contain information about the material, topics and dates of application.

2. The score for collaboration to the group of students, and so also the list of metrics for measure de $\mathrm{Cl}$ (See Appendix II).

Execution.- The execution will be guided according to the process of Fig 1, which establishes the activities to be fulfilled by both the teacher (s), and the students by each topic.

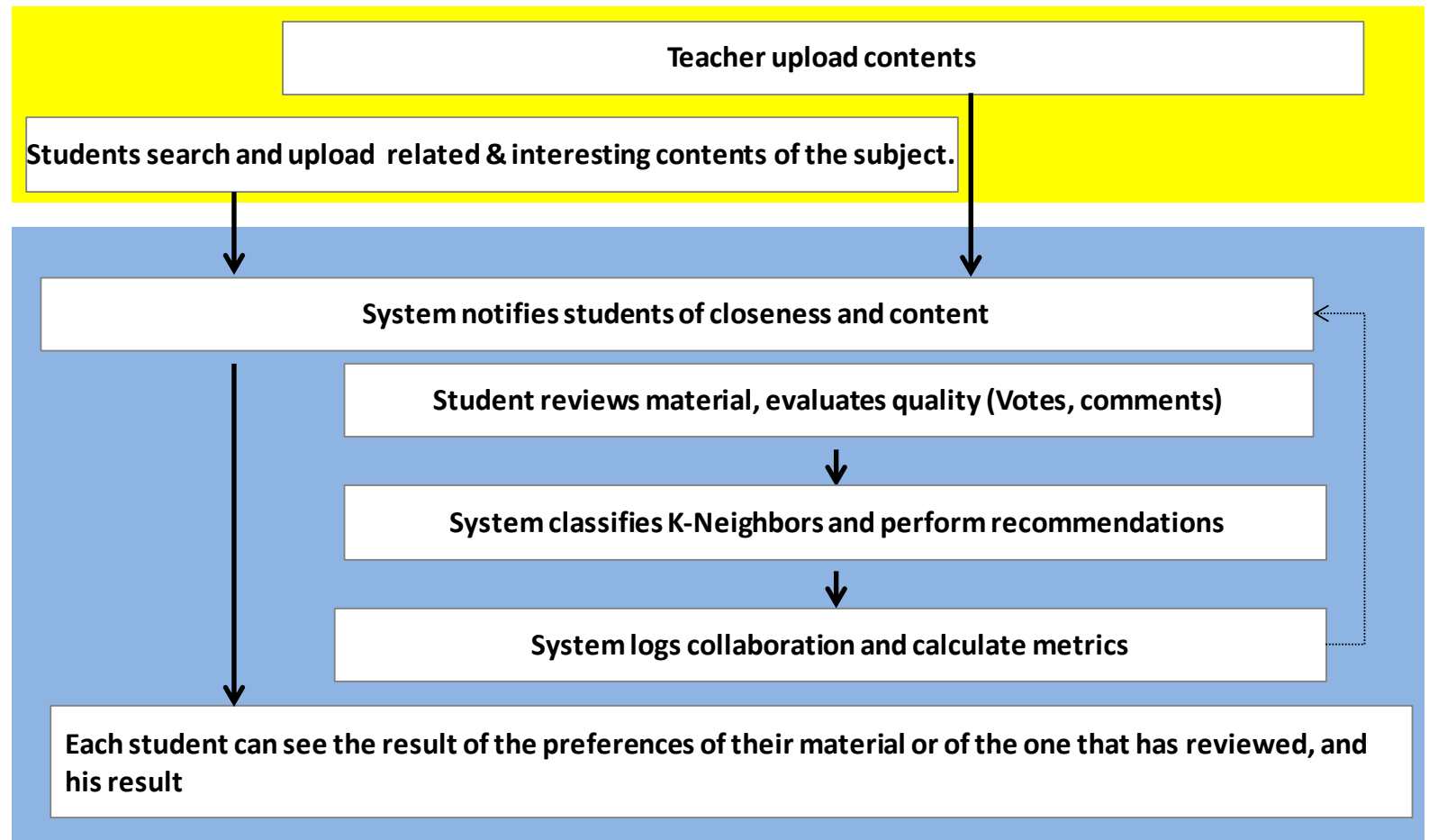

Figure 1. - Execution process.

As it is possible to see in Fig. 1 the $\mathrm{Cl}$ process involves a complete and constant collaboration \& competition relationship between teacher and students, and also at the same time there is a close relationship between (each other) students, therefore is reasonable to think of CIRS as an IC tool in the class.

\subsection{Recommender engine}

Collaborative filtering approach is applied. The recommender engine (Fig. 2) classify by the student preferences in relation with the proposal from others classmates. The preferences has tagging with the comments, votes or information sharing with others users. Additionally the first filter applied is given by the individual profile. The individual profiles are classified according to class, working group \& teacher

Each time that the user generates a new preference tag, the RS engines notify its workgroup. Additional when one user received a positive vote all the workgroup is also notified, inviting to do new contributions. 
The filtering method develops a search by groups, neighbors, and neighbors preferences. The recommendations order is presented according to ranking preferences by document proposed. The ranking preferences are computed by the sum of emoticon ${ }^{\uparrow}$ value in the vote.

The recommendations are tagged four sections: Recommenders items, favorites, recent lectures, or by categories. The recommender engine classifies by individual, or together all the tagging elements.

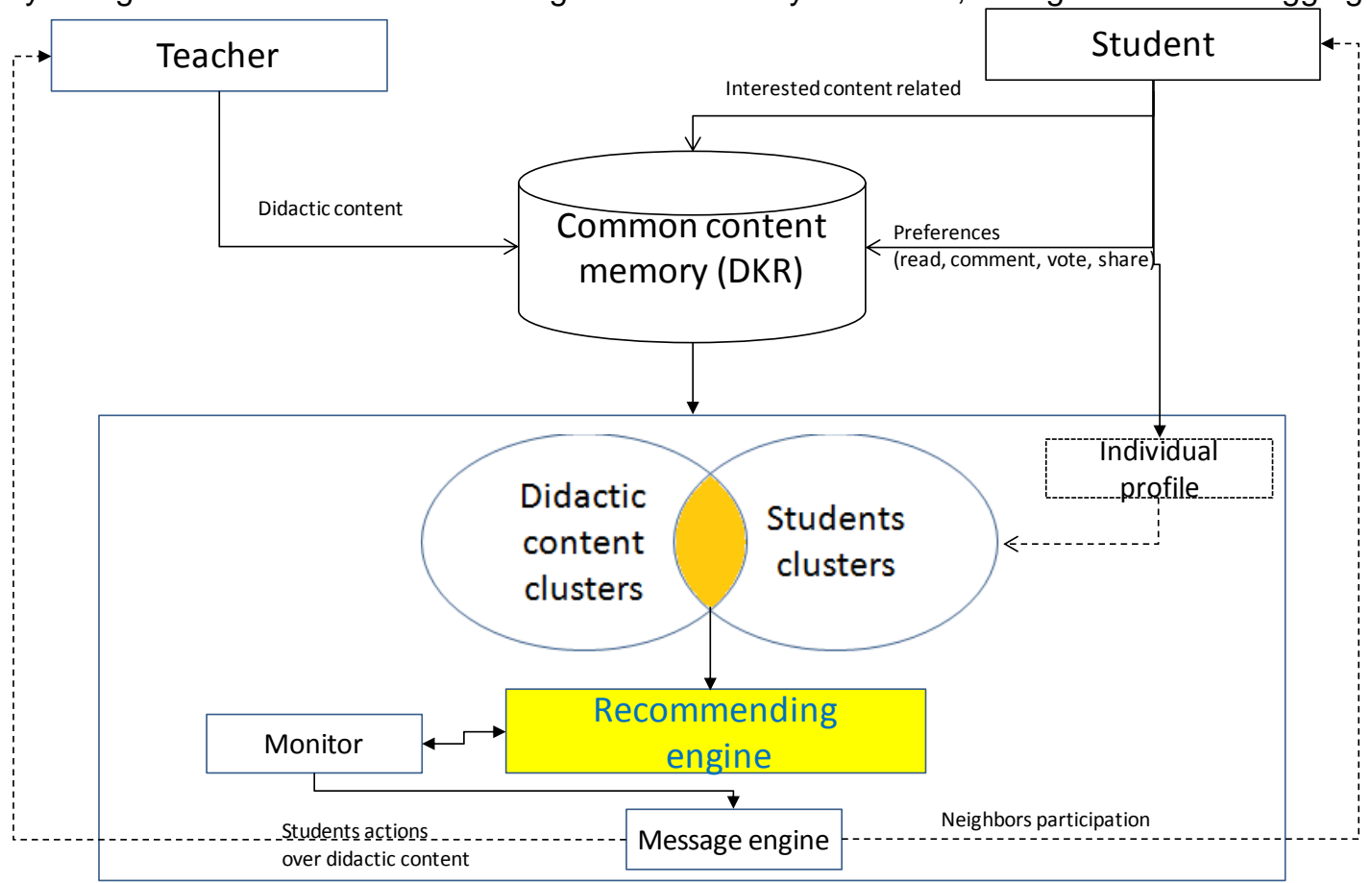

Figure 2. - Conceptual design of recommender engine.

- Recommender's items contain the information together all the tagging elements.

- Favorites are the items that the user have vote with a positive emoticon that mean "I like" or " I love".

- Recent lectures from the last month into the category of individual profile.

- Categories related with the specific subject.

\section{EMPIRICAL EXPERIENCE \& RESULTS}

In this section, the empirical evidence of CIRS application through a web tool (Appendix I) is described. CIRS was used by one group of student from the University of the Armed Forces of Ecuador ESPE in the academic year 2016-2017 in the months of October 2016 till January of 2017. The number of students were 24 (18 Masculine, 6 Feminine) the average of age was 20 years age. The students had to resolve several topics in the subject of Social Project Manager Administration. By each task the students and teacher followed the process represented in the Fig 1.

The outcomes to CIRS application are shown by its use and users behaviors. The CIRS was used by 24 students the participation index was 15 by user, and the access was 38 times by user in four months.

The behavioral results in CIRS was produced by interaction data collected to illustrate the potential of the system on given relevant and useful information by the recommender engine. The data registered by students allowed the description of the connections and members centrality within the network. We used NodeXL for modeling the student interaction. The analysis of the exploration was done as a network of direct relations between nodes; additionally a clustering of vertex clusters was performed.

\footnotetext{
${ }^{1}$ Each emoticon has a value that allows compute the preference results. The emoticon values are applied according to emotion positive or negative [31].
} 
The Fig. 3 shows nodes of different sizes represent the degree of student outputs or interactions with other students' proposals. There is a concentration in the interaction with the proposals of the class itself; however some students interact with other material available in the common memory.

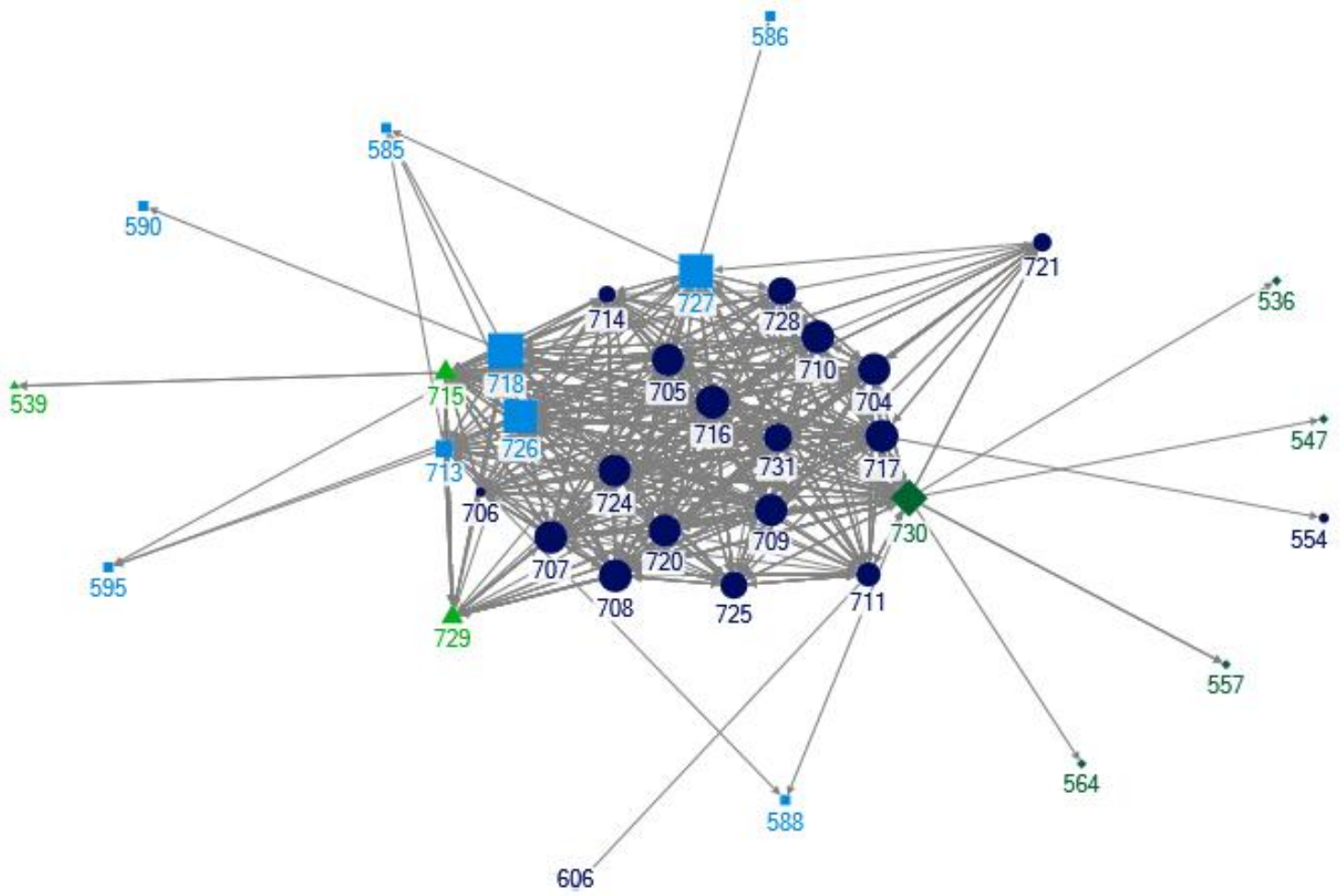

Figure 3. - Student interaction.

The number of groups generated by the clustering was four. Each group presented a some insight of their behavior. The highest concentration was confirmed by 19 vertexes, the student content mostly review was about "Complexity in the logical framework ". Therefore this topic allowed to the teacher considering analyzed in deep this particular behaviors and accuracy in the topic understanding.

In the other hand, the relation between propose a interest content and give feedback to the existing content was 5,91 and the standard deviation 4,45.

The outcomes, have relation with [12], who mentions that individuals interactions with common memory by converting tacit knowledge into explicit and vicious. CIRS was created primarily to promote the use of shared memory with shared repository of collaborative learning data. The results presented evidence a favorable effect in the collaboration, represented by the degree of centrality of the nodes, which according to (Cho et al., 2007) cited by [22] High degree of centrality is important because it shows a positive association with performance. The performance is improved through individual access to resources. In addition, [32] defines collaboration as an activity that cannot be divided into small pieces and is concentric in this sense there is concentration on the material of the classmates themselves. Finally, [23] argues that collective intelligence systems must help synergy among all actors in a collective, and CIRS fulfills these condition. Therefore, in this context where the collaboration \& competition is presented the $\mathrm{Cl}$ emerge.

\section{CONCLUSIONS}

The objective of the presented work is to share the progress on a research program, which purpose is to provide processes, tools and resources for fostering the collective intelligence with recommender system in the class.

There are several algorithms for classification, in this experience we focus on the collaboration how the best way for improve the recommendation and increasing the student participation, fostering the self-learning. 
The application of CIRS has shown evidence on the usefulness of the tools in the collaboration and participation into the class. The usefulness of the tool is considered because the evaluation according to the contributions, preferences and individual member's profiles, presents a new field for engaged the student learning. It's improves the student motivation, and it helps to the students to discover new content of interest in an easy way, moreover, It allows saves time in the search and classification of teaching material of interest, and finally it's fosters specialized reading, inspires competence as a means of learning.

In the other hand, It's gives the teacher the ability to generate reports of trends and behaviors of their students, real-time assessment of the quality of learning material, therefore accuracy the quality of didactic material, but also some insight about improve the didactic material, and increasing the performance of teaching-learning process.

The CIRS can be applied in several fields for instance: Training courses, types of training in different modalities, investigations of student behavior and preferences analysis, analysis of trends and quality of materials.

The proposed instructional design and the corresponding web tool are the result of a creative combination of theoretical and practical perspectives. From this point, with a consistent instructional design, it will be possible to continue with the development of new features oriented to make recommendations on the continuous improvement to the state of art in the field of collective intelligence and recommender system in the teaching-learning process.

\section{ACKNOWLEDGEMENTS}

We thank the Department of Human and Social Sciences of the University of the Armed Forces ESPE (ECUADOR).

\section{REFERENCES}

[1] Jung, J. J. (2017). Computational Collective Intelligence with Big Data: Challenges and Opportunities.

[2] Woolley, A. W., Chabris, C. F., Pentland, A., Hashmi, N., \& Malone, T. W. (2010). Evidence for a collective intelligence factor in the performance of human groups. science, 330(6004), 686688.

[3] De Maio, C., Fenza, G., Loia, V., \& Orciuoli, F. (2017). Unfolding social content evolution along time and semantics. Future Generation Computer Systems, 66, 146-159.

[4] Chianese, A., Marulli, F., Piccialli, F., Benedusi, P., \& Jung, J. E. (2017). An associative engines based approach supporting collaborative analytics in the internet of cultural things. Future generation computer systems, 66, 187-198.

[5] Shafiq, S. I., Sanin, C., Szczerbicki, E., \& Toro, C. (2017). Towards an experience based collective computational intelligence for manufacturing. Future Generation Computer Systems, 66, 89-99.

[6] Lee, O. J., \& Jung, J. E. (2017). Sequence clustering-based automated rule generation for adaptive complex event processing. Future Generation Computer Systems, 66, 100-109.

[7] Lops, P., De Gemmis, M., \& Semeraro, G. (2011). Content-based recommender systems: State of the art and trends. In Recommender systems handbook (pp. 73-105). Springer US.

[8] Achakulvisut, T., Acuna, D. E., Ruangrong, T., \& Kording, K. (2016). Science Concierge: A fast content-based recommendation system for scientific publications. Cornell University Library.

[9] Burke, R. (2007). Hybrid web recommender systems. The Adaptive Web, 377-408. http://doi.org/10.1007/978-3-540-72079-9_12

[10] Dascalu, M.-I., Bodea, C.-N., Mihailescu, M. N., Tanase, E. A., \& Ordoñez De Pablos, P. (2016). Behaviour \&amp; Information Technology Educational recommender systems and their application in lifelong learning Educational recommender systems and their application in lifelong learning. Behaviour \& Information Technology, 354, 290-297.

http://doi.org/10.1080/0144929X.2015.1128977 
[11] Herlocker, J. L., Konstan, J. a, \& Riedl, J. (2000). Explaining collaborative filtering recommendations. In Proceedings of the 2000 ACM conference on Computer supported cooperative work (pp. 241-250). http://doi.org/10.1145/358916.358995

[12] Levy, P. (2015). Collective Intelligence for Educators. Educational Philosophy and Theory, 47(8), 749-754. http://doi.org/10.1080/00131857.2015.1053734

[13] Mahmood, T., \& Ricci, F. (2007). Towards learning user-adaptive state models in a conversational recommender system. Proceedings of the 15th Workshop on Adaptivity and User Modeling in Interactive Systems, ABIS, 7, 373-378.

[14] Oh, J., Jeong, O., \& Lee, E. (2013). Place Recommendation System, 169-176.

[15] Patel, A., \& Balakrishnan, A. (2009). Generic framework for recommendation system using collective intelligence. International Conference for Internet Technology and Secured Transactions.

[16] Ryang, H., Yun, U., Pyun, G., Lee, G., \& Kim, J. (2014). Ranking algorithm for book reviews with user tendency and collective intelligence. Multimedia Tools and Applications, 6209-6227. http://doi.org/10.1007/s11042-014-2101-4

[17] Sacín, C. V., Agapito, J. B., Shafti, L., \& Ortigosa, A. (2009). Recommendation in Higher Education Using Data Mining Techniques. Proceedings of the 2nd International Conference on Educational Data Mining, 191-199. Retrieved from http://www.educationaldatamining.org/EDM2009/uploads/proceedings/vialardi.pdf

[18] Schafer, J., Frankowski, D., Herlocker, J., \& Sen, S. (2007). Collaborative Filtering Recommender Systems. The Adaptive Web, 291-324. http://doi.org/10.1007/978-3-540-720799_9

[19] Secundo, G., Dumay, J., Schiuma, G., \& Passiante, G. (2016). Managing intellectual capital through a collective intelligence approach. Journal of Intellectual Capital, 17(2), 298-319. http://doi.org/10.1108/JIC-05-2015-0046

[20] Viejo Fernández, X. (2015). Sistemas de Recomendación de Contenidos para Libros Inteligentes. Dialectologia: revista electrònica.

[21] Zhou, J., Luo, T., \& Lin, H. (2010). A novel recommendation system with collective intelligence. Proceedings - 2010 IEEE 2nd Symposium on Web Society, SWS 2010, 151-157. http://doi.org/10.1109/SWS.2010.5607461

[22] Cadima, R., Ferreira, C., Monguet, J., Ojeda, J., \& Fernandez, J. (2010). Promoting social network awareness: A social network monitoring system. Computers \& Education, 54(4), 1233 1240. http://doi.org/10.1016/j.compedu.2009.11.009

[23] Glenn, J. C. (2013). Collective intelligence systems and an application by The Millennium Project for the Egyptian Academy of Scientific Research and Technology. Technological Forecasting and Social Change, 97, 7-14. http://doi.org/10.1016/j.techfore.2013.10.010

[24] Levy, P. (2015). Collective Intelligence for Educators. Educational Philosophy and Theory, 47(8), 749-754. http://doi.org/10.1080/00131857.2015.1053734

[25] Ricci, F., Rokach, L., \& Shapira, B. (2011). Introduction to recommender systems handbook (pp. 1-35). Springer US.

[26] Bridge, D., G" oker, M., McGinty, L., Smyth, B.: Case-based recommender systems. The Knowledge Engineering review 20(3), 315-320 (2006)

[27] Ricci, F., Cavada, D., Mirzadeh, N., Venturini, A.: Case-based travel recommendations. In: D.R Fesenmaier, K.Woeber, H.Werthner (eds.) Destination Recommendation Systems: Behavioural Foundations and Applications, pp. 67-93. CABI (2006)

[28] Arazy, O., Kumar, N., Shapira, B.: Improving social recommender systems. IT Professional 11(4), 38-44 (2009)

[29] Ben-Shimon, D., Tsikinovsky, A., Rokach, L., Meisels, A., Shani, G., Naamani, L.: Recommender system from personal social networks. In: K. Wegrzyn-Wolska, P.S. Szczepaniak (eds.) AWIC, Advances in Soft Computing, vol. 43, pp. 47-55. Springer (2007) 
[30] Núñez Valdéz, E. R. (2012). Sistemas de recomendación de contenidos para libros inteligentes.

[31] Meza, J., Ortiz, O., Vaca-Cardenas, M., Roman, S., \& Monguet, J. M. (2017). CIR: Fostering Collective Creativity. In G. Vincenti, A. Bucciero, M. Helfert, \& M. Glowatz (Eds.), E-Learning, EEducation, and Online Training: Third International Conference, eLEOT 2016, Dublin, Ireland, August 31 -- September 2, 2016, Revised Selected Papers (pp. 145-152). Cham: Springer International Publishing. http://doi.org/10.1007/978-3-319-49625-2_18

[32] Malone, T. W., Laubacher, R., \& Dellarocas, C. (2010). The Collective Intelligence Genome THE LEADING. MIT Sloan Management Review, 51(51303), 21-31. http://doi.org/10.1109/EMR.2010.5559142

\section{Appendix I. Web tool interfaces}

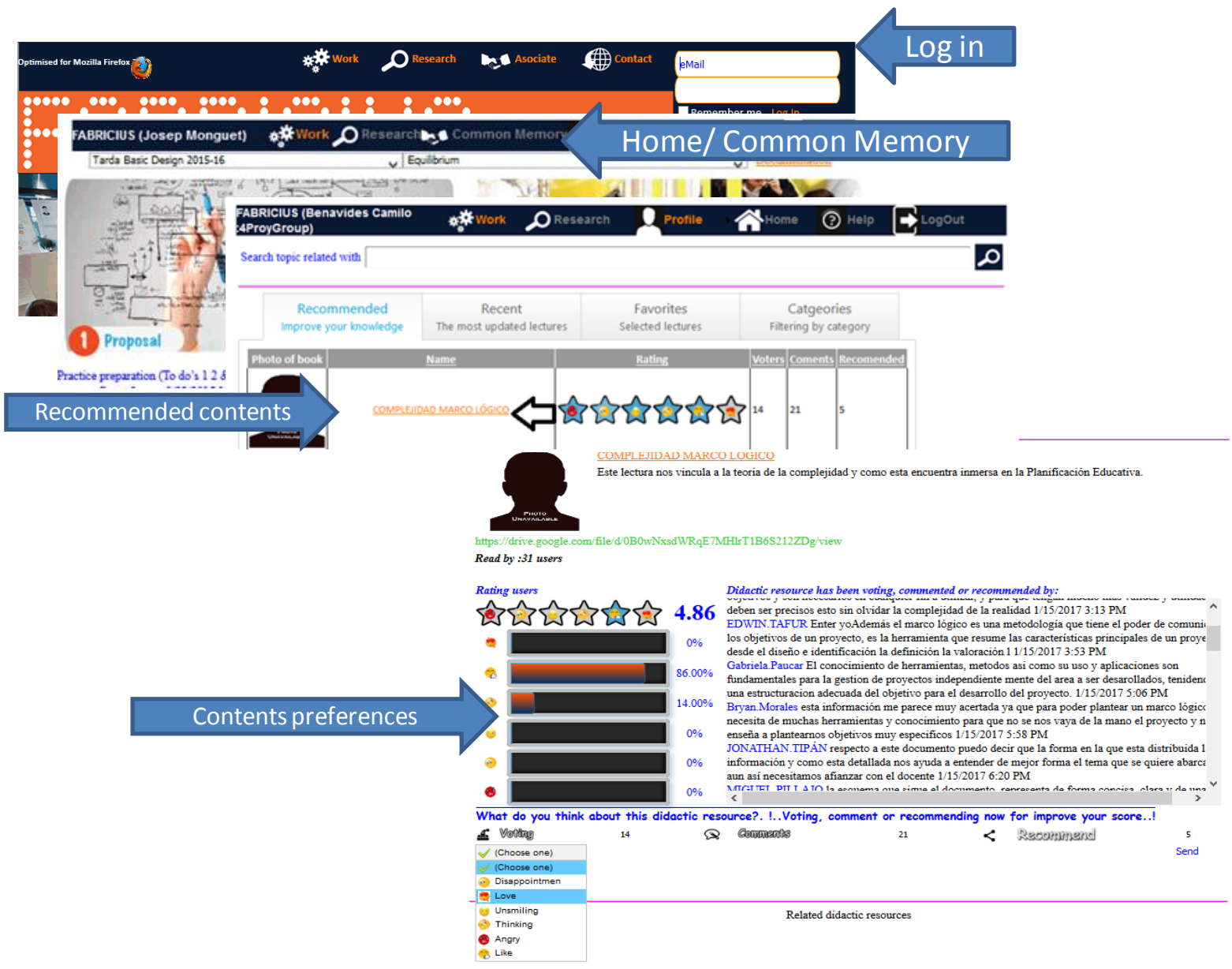

Figure 4. Main interfaces of CIRS

\section{Appendix II. Collective Intelligence metrics}

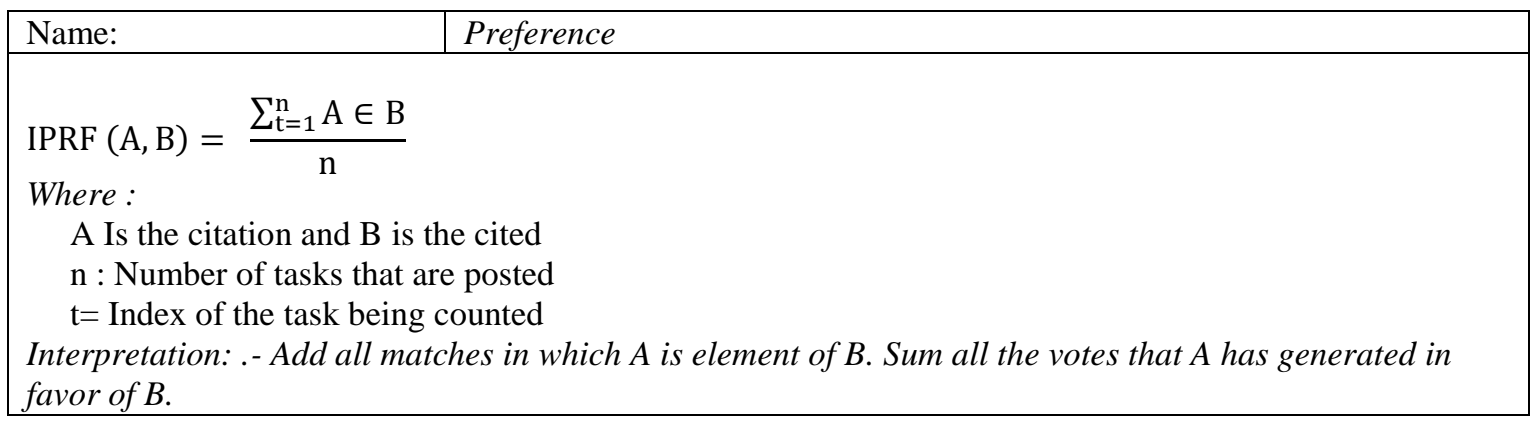




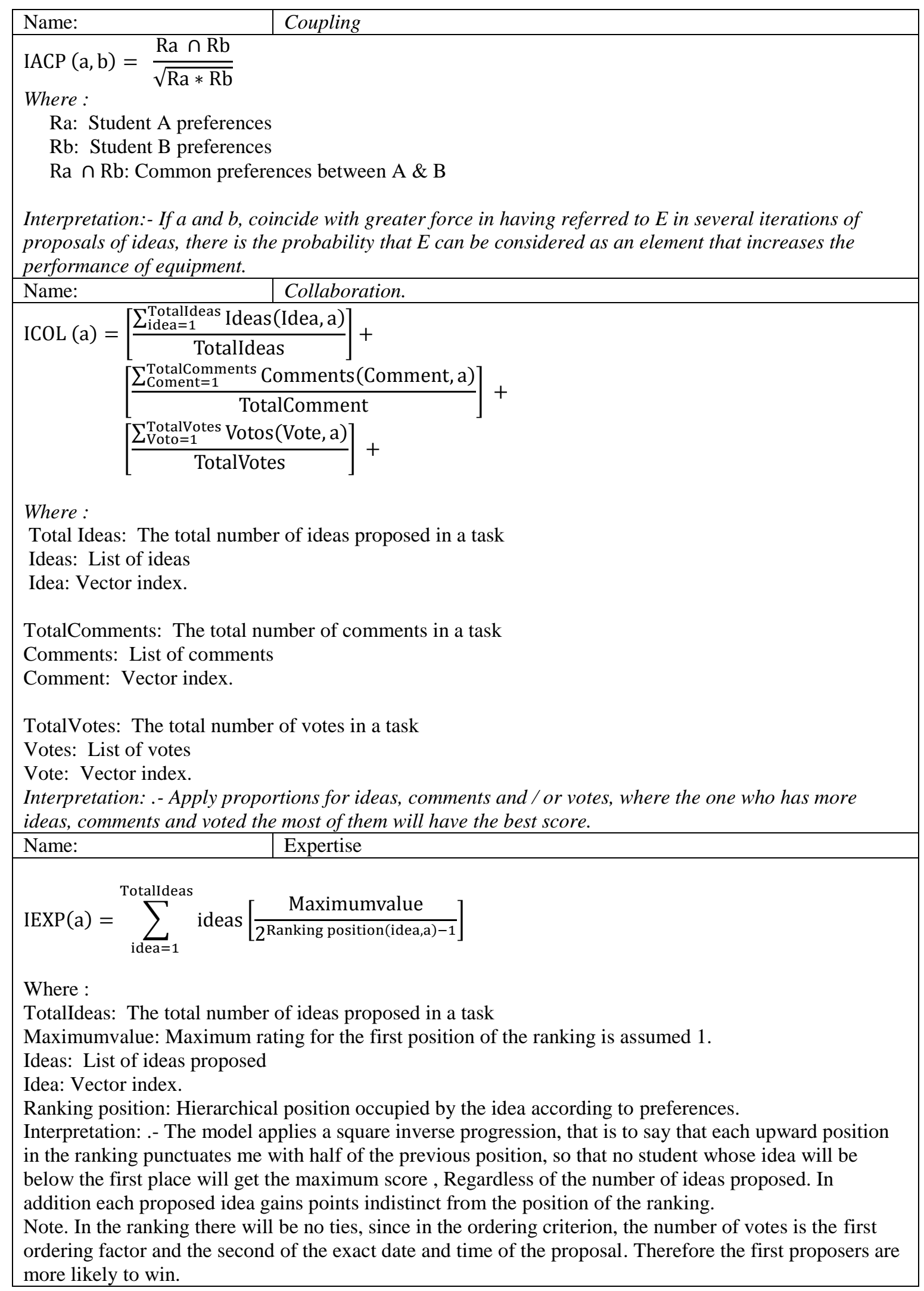

